\title{
Ecologia da polinização de Raphiodon echinus (Nees \& Mart.) Schauer (Lamiaceae) em Petrolina, PE, Brasil
}

\author{
Carla Tatiana de Vasconcelos Dias ${ }^{1}$ e Lúcia Helena Piedade Kiill2,3
}

Recebido em 20/02/2006. Aceito em 3/04/2007

\begin{abstract}
RESUMO - (Ecologia da polinização de Raphiodon echinus (Nees \& Mart.) Schauer (Lamiaceae) em Petrolina, PE, Brasil). Raphiodon echinus é uma espécie de hábito rasteiro, que ocorre espontaneamente em áreas de caatinga. No presente trabalho foram observados a biologia reprodutiva desta espécie com o objetivo de contribuir com informações sobre sua ecologia da polinização. As observações foram feitas em áreas de caatinga da Embrapa Semi-Árido, em Petrolina, PE. Para os experimentos de autopolinização espontânea, autopolinização manual, apomixia, geitonogamia, xenogamia, botões foram ensacados, emasculados e polinizados, quando necessário. Flores foram marcadas para estimar a polinização em condições naturais. Os visitantes florais foram observados das $7 \mathrm{~h} 30$ min às $16 \mathrm{~h} 00$, totalizando 45 horas de observações. As flores de R. echinus são infundibuliformes, de coloração violeta, exalam odor adocicado e estão reunidas em glomérulos. A antese é diurna, assincrônica, sendo mais freqüente no período da manhã, por volta das 07h00. A duração das flores é de aproximadamente 10 horas e cada inflorescência apresenta número variado de flores/dia. As flores são visitadas por abelhas e borboletas. Centris hyptidis foi responsável por $26 \%$ do total das visitas e, de acordo com o comportamento e frequiência de visitas, foi considerada como polinizador efetivo desta espécie. Quanto ao sistema de reprodução, R. echinus é autógama facultativa, produzindo frutos por autopolinização manual (70\%), geitonogamia (63\%) e xenogamia (40\%).
\end{abstract}

Palavras-chave: Centris hyptidis, autogamia, Caatinga

\begin{abstract}
Pollination ecology of Raphiodon echinus (Nees \& Mart.) Schauer (Lamiaceae) in Petrolina, Pernambuco State, Brazil). Raphiodon echinus is a prostrate weedy species that occurs in the Caatinga. In this work, floral biology and reproductive system were observed in order to understand the pollination ecology of this species. Observations were made at Embrapa Semi-Árido, in Petrolina, Pernambuco. For the self-pollination, apomixis, geitonogamy and xenogamy experiments, buds were protected, emasculated, and pollinated when necessary. Flowers were tagged to estimate pollination success under natural conditions. Floral visitors were observed on different days from 7:30 a.m. to 4:00 p.m., for a total of 45 hours. The violet flowers of $R$. echinus are infundibuliform and give off a sweet scent; they are grouped in long-pedunculate spherical heads. Anthesis is diurnal and is more frequent in the morning around 7:00 a.m. Flowers last for about ten hours and the number of flowers that open daily on each inflorescence varies. The flowers are visited by bees and butterflies. Centris hyptidis was responsible for $26 \%$ of total visits. Based on behavior and frequency of visits, this bee was considered to be the effective pollinator of $R$. echinus. As regards the reproductive system, $R$. echinus is self-compatible and produces fruits by manual self-pollination (70\%), geitonogamy (63\%) and xenogamy (40\%).
\end{abstract}

Key words: Centris hyptidis, autogamy, Caatinga

\section{Introdução}

O estudo das inter-relações entre plantas e polinizador tem sido objeto de pesquisa em diversas regiões do mundo e, no Brasil, esses estudos concentram-se principalmente na região Sudeste. Para as espécies ocorrentes no Nordeste, os primeiros estudos foram realizados a partir da década de 70 (Mori \& Orchard 1979; Mori et al. 1980; Ormond et al. 1984). A partir dos anos 90, essa linha de pesquisa tomou impulso, sendo desenvolvidos trabalhos relacionados com o tema (Vogel \& Machado 1991;
Pinheiro et al. 1991; Machado \& Sazima 1995; Aguiar et al. 1995).

Porém, estudos realizados com biologia floral, fenologia, mecanismos de polinização e sistemas de reprodução em espécies ocorrentes na Caatinga ainda são escassos (Machado 1996; Machado \& Lopes 2002), sendo que essas investigações enfocam principalmente uma ou poucas espécies (Machado \& Lopes 2003).

Entre os representantes da família Lamiaceae na Caatinga, destaca-se o gênero Raphiodon, monotípico, representado pela espécie Raphiodon echinus (Nees

\footnotetext{
Embrapa Semi-Árido, 56302-970 Petrolina, PE, Brasil (carltaty@yahoo.com.br)

Embrapa Semi-Árido, C. Postal 23, 56302-970, Petrolina, PE, Brasil

Autor para correspondência: kiill@cpatsa.embrapa.br
} 
\& Mart) Schauer e considerado como característico dessa região (Harley 2000). Esta espécie se destaca por apresentar como principais características a presença de cálice frutífero com lacínios espinescentes e hábito prostrado.

Além disso, $R$. echinus é considerada como invasora, típica da caatinga, sendo encontrada especialmente em áreas sujeitas a inundação temporária, a beira da estrada e em áreas de cultivo abandonadas e apresenta ampla distribuição no Brasil, sendo registrada nos Estados de Bahia, Pernambuco, Paraíba, Ceará e Minas Gerais (Harley 1988; 1995; 1996; 2002; Albuquerque \& Almeida 2002). Em estudos realizados para a região Nordeste, $R$. echinus é citado em levantamentos feitos em Pernambuco (Almeida \& Albuquerque 2002), Paraíba (Barbosa et al. 2004) e Bahia (Harley 1996).

Com relação à biologia reprodutiva, há poucas informações sobre a espécie na literatura. Em relação aos visitantes florais, Kiill et al. (2000) verificaram que as flores dessa Lamiaceae são visitadas por abelhas Apis mellifera e borboletas (Ascia monuste e Agraulis vanillae) em áreas de fruticultura irrigada, sendo somente as primeiras consideradas como polinizadores desta espécie.

Assim, o presente trabalho teve como objetivo estudar a biologia floral, polinização e sistema de reprodução de Raphiodon echinus na caatinga do sertão de Pernambuco, contribuindo com informações sobre as formas de reprodução e os mecanismos de polinização desta espécie.

\section{Material e métodos}

O presente trabalho foi desenvolvido em uma área da Embrapa Semi-Árido, no Município de Petrolina-

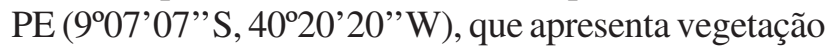
dominante do tipo caatinga arbustiva-arbórea, hiperxerófila.

Os trabalhos de campo foram desenvolvidos no período de janeiro a março/2003, entre 07:30h e 16:00h, envolvendo 17 indivíduos de Raphiodon echinus. Os indivíduos marcados foram observados semanalmente durante todo ciclo. Para verificar a viabilidade dos grãos de pólen, lâminas com as anteras foram preparadas com carmim acético 1,2\% (Radford et al. 1974) e cerca de 100 grãos de pólen foram avaliados por lâmina. A receptividade do estigma foi testada com Sudam III (Johansen 1940).

Os visitantes florais foram observados ao longo do período de floração, entre 7:30h e 16:00h. Para cada período (por ex., das 9:00h - 10:00h) foram feitas cinco observações em dias não consecutivos, totalizando 45 horas, durante as quais foram anotados a frequiencia, a duração e o comportamento dos principais visitantes florais.

Para determinar a estratégia reprodutiva da espécie, 15 inflorescências foram ensacadas, sendo as flores submetidas aos experimentos de autopolinização espontânea, autopolinização manual, apomixia, geitonogamia e xenogamia. Para cada tratamento utilizou-se 30 flores que foram emasculadas, quando necessário e submetidas aos diferentes tratamentos, sendo que o pólen usado nesses tratamentos foi obtido de flores previamente ensacadas. Inflorescências foram marcadas e observadas em condições naturais para verificar a eficiência da polinização natural.

\section{Resultados e discussão}

Raphiodon echinus é uma espécie que ocorre espontaneamente em locais abertos em área de caatinga e apresenta caule rasteiro, com folhas inteiras, cordiformes, com disposição oposta. As flores são pequenas (5 $\mathrm{mm}$ de diâmetro e $9 \mathrm{~mm}$ de comprimento), infundibuliformes, de cor violeta e estão reunidas em densos glomérulos axilares que contém, em média, 20-35 botões. O cálice é composto por 5 a 7 lacínios subulados que durante a frutificação tornam-se espinescentes. A corola é zigomorfa, bilabiada, com lábio superior formado por três lobos e inferior por dois. $\mathrm{O}$ androceu é constituído por quatro estames didínamos, sendo que as anteras e os filetes apresentam coloração roxa. O gineceu é formado por um ovário súpero, bicarpelar, estilete simples e estigma globoso. O estigma e estilete apresentam coloração roxa e ficam posicionados no lábio inferior da corola. Esta disposição e a coloração semelhante à da corola faz com essas estruturas fiquem pouco visíveis. O nectário se apresenta na forma de um disco glandular unilateralmente expandido.

Morfologicamente, as flores de $R$. echinus apresentam o padrão típico das Lamiaceae, caracterizado por apresentar flores diclamídeas, hermafroditas, pentâmeras, fortemente zigomorfas e bilabiadas, reunidas em densas inflorescências axilares (Huck 1992; Albuquerque \& Almeida 2002; ClabenBockhoff et al. 2004). De acordo com Pijl (1972), as flores desta espécie se enquadrariam no tipo "goela" com polinização nototríbica e segundo Percival (1969), estes tipos de flores restringem o acesso de visitantes, 
permitindo que somente aqueles com morfologia adequada (comprimento de língua, diâmetro corporal, etc.) teriam acesso ao néctar.

Segundo Faegri \& van der Pijl (1980), características morfológicas como forma, tamanho, cor, posição dos órgãos sexuais, localização do nectário, quantidade de néctar produzido, entre outras, estão diretamente associados ao tipo de polinizador e podem ser agrupadas nas chamadas síndromes de polinização. Comparando a morfologia observada para a espécie estudada com o padrão descrito para essas síndromes, verificamos que $R$. echinus apresenta atributos florais, tais como: simetria bilateral, órgãos sexuais ocultos na base dos lábios da corola, superfície para pouso e sustentação do visitante, cores vivas, emissão de odores adocicados, néctar oculto na base da corola e produzido em pequena quantidade, que caracterizam as flores melitófilas.

Além dessas características, as flores de $R$. echinus apresentam anteras envoltas pelo lobo mediano do lábio da corola, protegendo os grãos de pólen e funcionando como um mecanismo de polinização explosiva (Fig. 1a e 1b). Este mecanismo pode ser acionado pelo peso do visitante floral ou naturalmente, quando os tecidos florais começam a se desidratar, lançando os grãos de pólen na direção do estilete. Mecanismos de polinização explosiva também são descritos para os gêneros Eriope, Marsipianthes, Peltodon e Hyptis (Brantjes \& Vos 1981; Keller \& Armbruster 1989) e, de acordo com Huck (1992) podem representar uma resposta adaptativa a ambientes xéricos, no qual os gametófitos masculinos contidos nos grãos de pólen ficariam protegidos nas anteras até que os mesmos sejam lançados e transportados por um polinizador específico.

Além do mecanismo de polinização explosiva, observou-se que algumas flores encontram-se em posição invertida em relação às outras (flores ressupinadas). Em amostragem feita, verificou-se que $55,9 \%$ das flores (Tab. 1) apresentam as anteras posicionadas no lábio superior e gineceu no lábio inferior (Fig. 1c, seta 1), enquanto que em $44,1 \%$ são ressupinadas (Fig. 1c, seta 2). Este posicionamento invertido dos órgãos reprodutivos de R. echinus se deve a torção de $180^{\circ}$ do pedicelo de algumas flores da inflorescência. Com a inversão, esta espécie deposita pólen em locais distintos dos visitantes, favorecendo assim a polinização cruzada. Flores ressupinadas em Lamiaceae são descritas por Faegri \& van der Pijl (1980) como uma flor tipo goela invertida. Nilsson et al. (1985) sugeriram que o desenvolvimento deste tipo de

Tabela 1. Número de flores normais e ressupindas de Raphiodon echinus (Nees \& Mart.) Schauer encontrado por inflorescência.

\begin{tabular}{cccc}
\hline Inflorescência & $\begin{array}{c}\text { Flores } \\
\text { Normais }\end{array}$ & $\begin{array}{c}\text { Flores } \\
\text { ressupinadas }\end{array}$ & Total \\
\hline 1 & 7 & 5 & 12 \\
2 & 8 & 5 & 13 \\
3 & 6 & 7 & 13 \\
4 & 13 & 7 & 20 \\
5 & 4 & 6 & 10 \\
Total & 38 & 30 & 68 \\
$\%$ & 55,9 & 44,1 & 100,00 \\
\hline
\end{tabular}
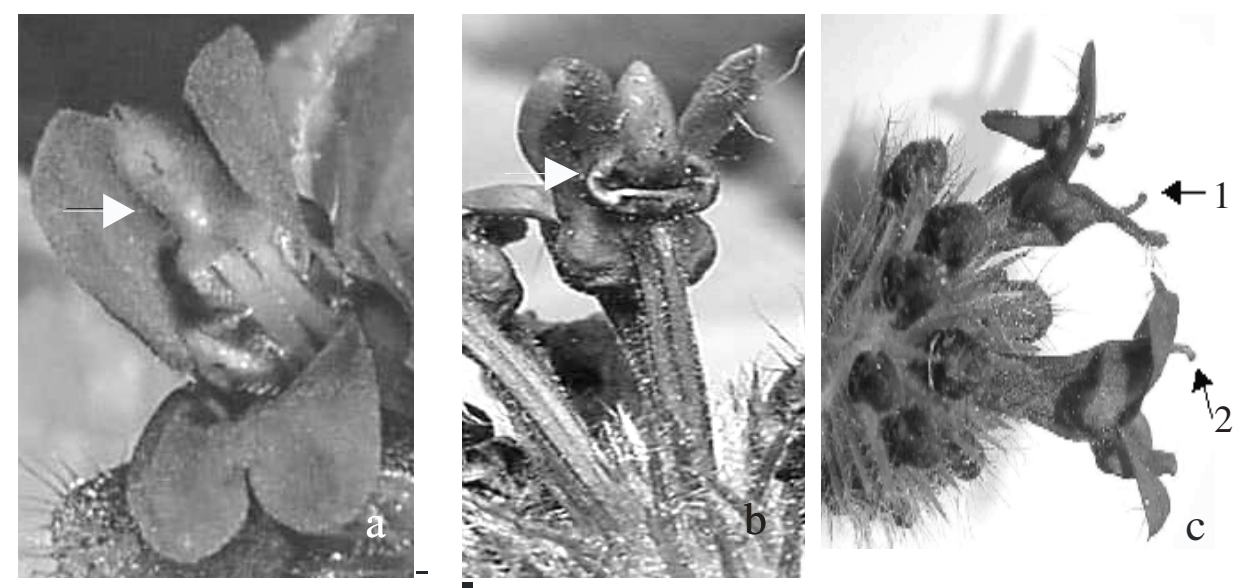

Figura 1. Detalhes das flores de Raphiodon echinus. (Nees \& Mart.) Schauer. a. Vista frontal da flor, mostrando filetes e o lobo da corola recobrindo as anteras (seta). b. Vista dorsal da flor, mostrando o sistema de alavanca na posição inicial (seta). c. Detalhe da inflorescência mostrando a posição das estruturas reprodutivas em flores normal (1) e ressupinada (2). Notar a localização do estigma (seta) nos dois tipos florais. 
980 Dias \& Kiill: Ecologia da polinização de Raphiodon echinus (Nees \& Mart.) Schauer (Lamiaceae) em Petrolina, PE...

flor é talvez uma resposta a forças seletivas exercitadas por algum grupo de agentes polinizadores. Faegri \& van der Pijl (1980), citando Tarraka (1972), sugeriram que a reversão da corola esteja ligada à inversão do posicionamento das estruturas reprodutivas localizadas no lábio superior para o inferior da flor, como o registrado para $R$. echinus.

Entre as Lamiaceae, as flores apresentam anteras e estigmas abrigados no mesmo lábio da flor (geralmente o superior), o que conseqüentemente favorecia a polinização nototríbica (Percival 1969; Proctor \& Yeo 1975; Faegri \& van der Pijl 1980; Claben-Bockhoff et al. 2004). Em R. echinus, entretanto, encontramos anteras e estigmas posicionados em lábios opostos da flor, o que consequientemente implica em contato com diferentes partes do corpo do visitante, evitando que possíveis autopolinizações ocorressem. Porém, se todas as flores mantivessem esse padrão, a polinização da espécie estaria comprometida, em conseqüência da separação espacial das estruturas reprodutivas. Tal fato não ocorre, em virtude da presença de flores ressupinadas. Com essa estratégia, a espécie permite que o pólen de flores com anteras situadas no lábio superior se deposite no dorso do visitante e entre em contato com o estigma da flor ressupinada e vice-versa. Assim, esta espécie deposita pólen em dois locais distintos dos visitantes, aumentando as chances de polinização cruzada.

A antese das flores é diurna, sendo que em cada inflorescência ocorre a abertura de 4-20 por dia. Durante as observações, verificou-se que a antese floral ocorre ao longo de todo o dia, sendo registrado maior número de flores abertas no período da manhã, entre $7 \mathrm{~h} 30 \mathrm{~min}$ e $10 \mathrm{~h} 00$. No período vespertino, o número de flores abertas é menor, ocorrendo com maior intensidade entre 14 e $15 \mathrm{~h} 00$. No momento da antese, há a emissão de odores adocicados, o estigma está receptivo, os grãos de pólen estão viáveis, porém as anteras se mantêm fechadas e protegidas pelo lobo mediano do lábio da corola.

Ao longo do dia, as flores do $R$. echinus foram visitadas por abelhas e borboletas, sendo que as primeiras totalizaram $38 \%$ do total de visitas e, as segundas, 62\% (Fig. 2). Entre as abelhas, Centris hyptidis foi a mais freqüente com $26 \%$ do total de visita, seguida por uma abelha não identificada com 9\%. Quanto ás borboletas, Agraulis vanillae foi a mais freqüente (47\%), seguida por Phoebis sp. e Eusema elatea, cada uma com $8 \%$ do total de visitas registrado.

Com relação ao comportamento de visitas, Centris hyptidis apresentou dois comportamentos distintos. No

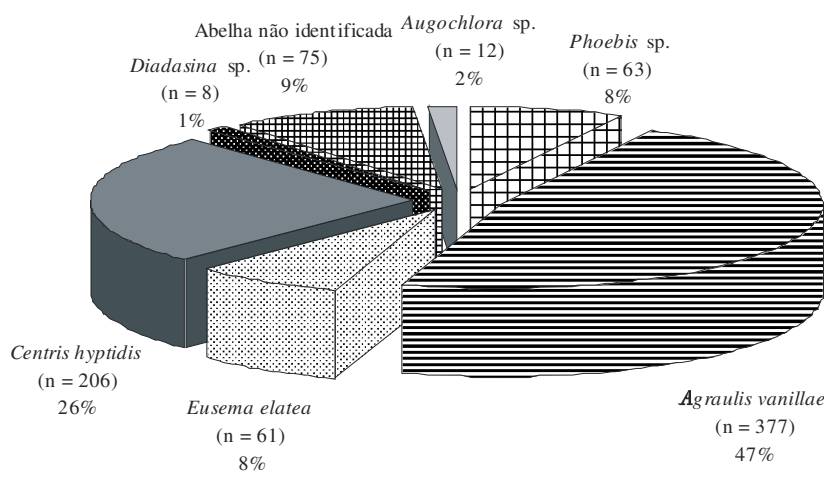

Figura 2. Visitantes florais de Raphiodon echinus (Nees \& Mart.) Schauer e seus respectivos números e porcentagens de visitas.

primeiro caso, aproximava-se de uma inflorescência, fazendo um zumbido que parecia ser característico da espécie, rapidamente pousava sobre o lábio da corola, fechava as asas, curvava o abdômen e então introduzia a língua no interior da corola. Com esse comportamento, a abelha tocava com a parte frontal da cabeça e peças bucais as anteras, ficando o pólen aí depositado e, com a região ventral, o estigma e estilete. No caso das flores ressupinadas, o inverso ocorria, ficando o pólen depositado ventralmente. Uma vez coletado o néctar, as abelhas retraiam a língua e ainda pousadas procuram outras flores disponíveis. Após a visita de três a quatro flores, a abelha levantava vôo, podendo visitar outras espécies floridas nas proximidades. O tempo de visita à inflorescência de $R$. echinus foi inferior a três segundos, variando de acordo com a quantidade de flores disponíveis. As demais abelhas (Auglochora sp., Diadasina sp. e a abelha não identificada) apresentaram o mesmo comportamento descrito acima.

Entre as borboletas, verificou-se que essas apresentaram comportamento semelhante, visitando as flores em busca de néctar, sem contatar as estruturas reprodutivas, sendo então considerada como pilhadores de néctar. Agraulis vanillae, uma vez pousada sobre as flores, distendiam a probóscide e introduziam no interior da corola para coletar o néctar sem, contudo, tocar as estruturas reprodutivas. Após a coleta desse recurso, a borboleta enrolava a probóscide e levantava vôo, visitando flores de outras espécies ou então outros indivíduos de $R$. echinus que se encontravam floridos nas proximidades. Comportamento semelhante foi observado por Kiill et al. (2000) em observações feitas em plantas invasoras em cultivo irrigado.

Com relação ao horário de visitas, verificou-se que entre as abelhas Centris hyptidis foi a mais freqüente em todos os horários, não sendo observada somente no período entre 8 e 9:00h. A abelha não identificada 
foi observada somente no período entre 11 e 14:00h, enquanto que Diadasina sp. e Augochlora sp. foram observadas em determinados horários (Fig. 3). Com relação às borboletas, Agraulis vanillae foi observada em todos horários com alta freqüência. As demais borboletas apresentaram freqüências bem menores.

De acordo com o comportamento e frequiência de visita apresentada, Centris hyptidis foi considerada como polinizador efetivo de R. echinus. Diadasina sp., Augochlora sp. e a abelha não identificada foram consideradas como polinizadores ocasionais desta Lamiaceae. Registros de Centris como polinizadores são registradas para espécies de Hyptis (Keller \& Armbruster 1989; Aguiar et al. 2003) e, segundo Huck (1992), as abelhas são os polinizadores mais freqüentes da família Lamiaceae, destacando-se Anthophoridae, Xylocopidae e Megachilidae com as famílias de abelhas encontradas como polinizadores do grupo.

Comparando os resultados aqui obtidos com as observações feitas por Kiill et al. (2000) em áreas irrigadas, verifica-se que Apis mellifera só foi observada em visita as flores de R. echinus na segunda situação, indicando que esta lamiaceae, em ambientes perturbados, estaria utilizando os serviços de polinização de outros insetos generalistas para ter garantida sua polinização, favorecendo assim sua distribuição em locais alterados.

Com relação ao sistema de reprodução, os experimentos de polinização indicam que o R. echinus é autocompatível, formando frutos a partir de autopolinização manual (Tab. 2). A ausência de frutos formados por autopolinização espontânea indica que a

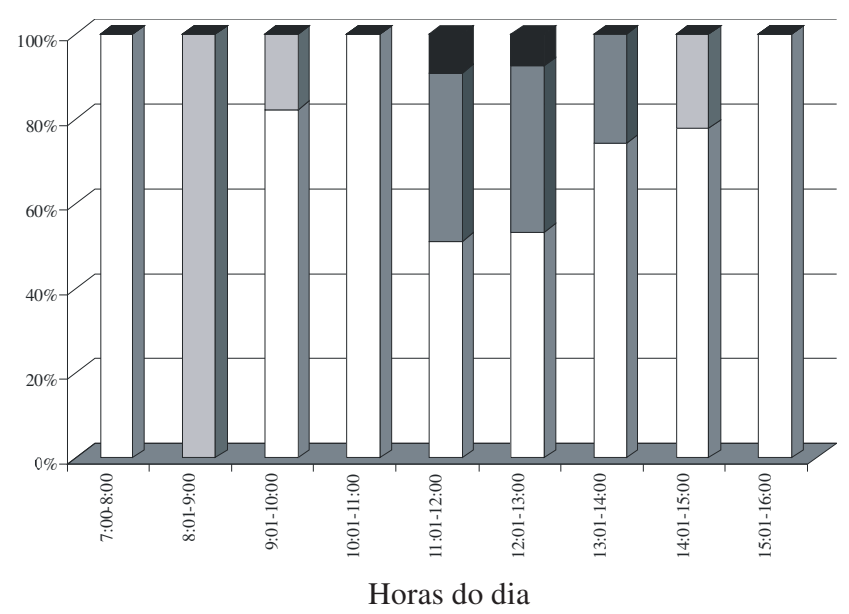

Figura 3. Visitantes florais de Raphiodon echinus (Nees \& Mart) Schauer e seus respectivos número de visitas registrados nos diversos horários de observação. ( $\square=$ Centris hyptidis; $\square=$ = Diadema sp.; = Abelha não identificada; $\mathbf{\square}=$ Augochlora sp.).
Tabela 2. Resultados do experimento de polinização de Raphiodon echinus (Nees \& Mart.) Schauer.

\begin{tabular}{lccr}
\hline Tratamentos & Flores & Frutos & $\%$ \\
\hline Condições naturais & 30 & 30 & 100 \\
Autopolinização espontânea & 30 & 0 & 0 \\
autopolinização manual & 30 & 21 & 70 \\
Apomixia & 30 & 9 & 30 \\
Geitonogamia & 30 & 19 & 63 \\
Xenogamia & 30 & 12 & 40 \\
\hline
\end{tabular}

separação espacial do androceu e gineceu é uma barreira reprodutiva, sendo que a espécie necessita de um agente polinizador para alcançar o sucesso reprodutivo. As maiores taxas de frutificação foram registradas em condições naturais indicando a eficiência dos agentes polinizadores. Quanto aos experimentos de geitonogamia e xenogamia foram registradas, respectivamente, 63 e $40 \%$, sendo estas bem inferiores as registradas em condições naturais. Estes resultados podem ser consequiência da manipulação das flores durante o processo de emasculação. Frutos apomíticos também foram obtidos, com taxas de $30 \%$.

Os dados obtidos indicam que $R$. echinus é autocompatível, porém necessita de um agente polinizador para garantir o sucesso reprodutivo. Em área de Caatinga, Centris hyptidis foi considerada o polinizador efetivo desta espécie e as demais abelhas, polinizadores ocasionais.

\section{Referências bibliográficas}

Aguiar, C.M.L.; Martins, C.F.; Moura \& A.C.A. 1995. Recursos florais utilizados por abelhas (Hymenoptera, Apoidea) em área de Caatinga (São João do Cariri, Paraíba). Revista Nordestina de Biologia 10: 101-117.

Aguiar, C.M.L.; Zanella, F.C.V.; Martins, C.F. \& Carvalho, A.L. 2003. Plantas visitadas por Centris spp. (Hymenoptera: Apidae) na Caatinga para obtenção de recursos florais. Neotropical Entomology 32(2): 247-259.

Albuquerque, U.P. \& Almeida, C.F.C.B.R. 2002. Diversidade da Família Labiatae em Pernambuco. Pp. 295-304. In: M. Tabarelli \& J.M.C. Silva (orgs.). Diagnóstico da Diversidade de Pernambuco. Recife, Secretária de Ciência, Tecnologia e Meio Ambiente. v.1.

Barbosa, M.R.; Agra, M.F.; Sampaio, E.V.S.B.; Cunha, J.P. \& Andrade, L.A. 2004. Diversidade Florística na Mata do Pau-Ferro. Pp. 111-122. In: M. Tabarelli; J.J.P. Cabral \& K.C. Porto (orgs.). Brejos de Altitude em Pernambuco e Paraíba: história natural, ecologia e conservação. Brasília, DF. MMA/UFPE. (SérieBiodiversidade, 9). 
982 Dias \& Kiill: Ecologia da polinização de Raphiodon echinus (Nees \& Mart.) Schauer (Lamiaceae) em Petrolina, PE...

Brantjes, N.B.M. \& Vos, O.C. 1981. The explosive release of pollen in flowers of Hyptis (Lamiaceae). New Phytologist 87: 425-430.

Claben-Bockhoff, R.; Speck, T.; Tweraser, E.; Wester, P.; Thimm, S. \& Reith, M. 2004. The staminal lever mechanism in Salvia L. (Lamiaceae): a Key innovation for adaptive radiotion? Organisms Diversity \& Evolution 4: 189-205.

Faegri, K. \& Pilj, L. van der. 1980. The principles of pollination ecology. Oxford, Pergamon Press.

Harley, R.M. 1988. Evolution and distribution of Eriope (Labiatae) and is relatives in Brasil. Pp. 71-80. In: Proceedings of a workshop on Neotropical Distribution Patterns. Rio de Janeiro, Academia Brasileira de Ciências.

Harley, R.M. 1995. Labiatae - Flora of the Pico das Almas, Chapada Diamantina, Bahia, Brazil. In: B.L. Stannard (ed.). London, Kew, Royal Botanic Garden.

Harley, R.M. 1996. The Labiatae of Bahia: A preliminary checklist. Feira de Santana, Sitientibus 15: 11-21.
Harley, R. 2000. In search of Labiatae in Eastern Brazil. Vitex 1: 5-7.

Harley, R.M. 2002. Distribuição das espécies de Labiatae na caatinga. Pp. 49-90. In: E.V.S.B. Sampaio; A.M. Giulietti; J. Virginio \& C.F.L. Gamarra-Rojas (eds.). Vegetação e flora da caatinga. Contribuição ao Workshop Avaliação e Identificação de Ações Prioritárias para a comunicação, Utilização Sustentável e Repartição dos Benefícios da Biodiversidade do Bioma Caatinga, PE. Recife, APNE / CINP.

Huck, R.B. 1992. Overview of pollination biology in the Lamiaceae. Pp. 167-181. In: M.R. Harley \& T. Reynolds (eds.). Advances in Labiate Science. Kew, Royal Botanic Gardens.

Johansen, D.A. 1940. Plant microtechnique. New York, McGraw-Hill Book Company.

Keller, S. \& Armbruster, S. 1989. Pollination of Hyptis capitata by eumenid wasps in Panama. Biotropica 21: 190-192. 